\section{Amniotic membrane transplantation using fibrin glue in pterygium surgery: a comparative randomised clinical trial}

Department of

Ophthalmology, Baskent

University School of

Medicine, Ankara, Turkey

\section{Correspondence:}

C Kucukerdonmez,

Department of

Ophthalmology,

Baskent University

School of Medicine,

Fevzi Cakmak Bulvari,

10. sokak,

Bahcelievler 06490

Ankara-Turkey

Tel: + 0903122150 349;

Fax: + 0903122237333.

E-mail: drcemk@

hotmail.com

Received: 7 December 2008 Accepted in revised form: 24 April 2009

Published online: 5 June 2009

Conflict of interest: None.

\begin{abstract}
Purpose To compare the results of amniotic membrane transplantation (AMT) using fibrin glue $v s$ vicryl sutures in pterygium surgery. Methods We carried out a prospective, randomised clinical study of 70 eyes ( 70 patients) with primary pterygium. After the removal of pterygium, patients were randomised to undergo AMT using fibrin glue (Tisseel, 32 eyes) or 8-0 vicryl sutures (38 eyes). Clinical examination and digital photographing were performed at each visit and the patients were followed up for at least 12 months. Post-operative symptoms in the first month were evaluated according to a fivepoint scale. Final appearances were graded from 1 to 4 in which grade 4 represented true (corneal) recurrence and grade 3 indicated conjunctival recurrence.

Results The average operation time in the fibrin glue and suture groups were $11.2 \pm 2.4 \mathrm{~min}($ mean $\pm S D)$ and $18.7 \pm 2.2 \mathrm{~min}$, respectively $(P=0.018)$. Significantly fewer post-operative symptoms were observed in the fibrin glue group at post-operative days 1, 7, and $14(P<0.05$ for all). At the end of the follow-up, true recurrence (grade 4) was developed in three eyes (9.4\%) in the fibrin glue group, and in four eyes $(10.5 \%)$ in the suture group $(P=0.33)$. The rates of conjunctival recurrence (grade 3) were $21.9 \%$ (seven eyes) and $23.7 \%$ (nine eyes) in the fibrin glue and suture groups, respectively $(P=0.38)$. Conclusions Amniotic membrane grafts can be successfully attached without any major complication in patients undergoing pterygium surgery. In addition, it is effective in shortening the duration of surgery and
\end{abstract}

C Kucukerdonmez, A Karalezli, YA Akova and M Borazan

preventing post-operative discomfort.

Although there seems to be no difference in the recurrence rates and cosmetic outcomes between both groups, neither technique represents best results.

Eye (2009) 24, 558-566; doi:10.1038/eye.2009.136; published online 5 June 2009

Keywords: AMT; fibrin glue; pterygium

\section{Introduction}

Pterygium is a common fibrovascular proliferative disease affecting the ocular surface, which may result in visual deterioration from encroachment of the visual axis, progressive scarring, and irregular astigmatism. There are various surgical techniques for pterygium, however, recurrence remains a major concern. Conjunctival autografting (CA) after pterygium excision is generally regarded as the procedure of choice because of its efficacy and long-term safety. ${ }^{1}$ However, it is not possible to cover large defects created in surgery for double-headed or large recurrent pterygia. Also, the need to reserve the conjunctiva for future filtrating surgery in glaucoma patients is another limitation of this technique.

Although comparative studies have presented wide variations in recurrence rates, amniotic membrane transplantation (AMT) remains an alternative for $\mathrm{CA}$, and the choice of this technique depends on individual surgeon's experience, training, and availability of the amniotic membrane. ${ }^{2}$

Commonly, $8-0$ vicryl or $10-0$ nylon sutures are used to fixate the amniotic membrane to the episcleral tissues and surrounding conjunctiva. 
Although it is safe and effective, more surgical expertise, technical ability, and surgical time are needed to secure the grafts with sutures. Both suture materials have been shown to cause comparable levels of post-operative discomfort and the choice of suture material mainly depends on the surgeon's preference. ${ }^{3}$ Providing a fast and reliable sutureless technique for graft fixation in pterygium surgery would potentially offer several advantages and avoid possible consequences of sutures, such as granuloma formation, giant papillary

conjunctivitis, and suture abcesses.

Earlier studies with the use of fibrin-based adhesives for attaching conjunctival grafts in pterygium surgery showed that this technique reduces the surgery time, suture-related complications and patient discomfort. ${ }^{4-8}$ In addition, the outcomes of AMT using fibrin glue for corneal ulceration, perforation, and ocular surface reconstruction have been reported in clinical and experimental studies. ${ }^{9-13}$ However, the results of pterygium surgery with AMT using fibrin tissue sealants have been evaluated in limited number of studies. Pfister and Sommers ${ }^{14}$ were the first to report the use of fibrin glue for amniotic membrane grafting in two patients with primary and in one with recurrent pterygium. In a study by Jain et al, ${ }^{15}$ the use of fibrin glue for AMT was found to be effective in reducing surgical time and postoperative patient discomfort. Furthermore, they have suggested that tucking the edges of the graft underneath the conjunctiva results in faster healing. However, their sample size was small, and the study was noncomparative. The last study regarding this issue was conducted by Kheirkhah et al, ${ }^{16}$ in which the role of conjunctival inflammation in surgical outcome after AMT has been investigated. They have found that the inflammation around the surgical site was significantly more common in eyes with sutures than fibrin glue. However, the retrospective nature and uncontrolled design of their study, together with non-comparable follow-up period between groups, were the potential drawbacks, as the authors have stated.

In this study, we aimed to assess the clinical and cosmetic outcomes of AMT using fibrin glue and to evaluate its effect on pterygium recurrence. Toward this goal, we conducted this prospective and randomised study to compare the surgical results with the use of vicryl sutures in patients undergoing pterygium excision.

\section{Materials and methods}

Seventy eyes of 70 patients with primary nasal pterygium who underwent pterygium excision with AMT consecutively between February 2006 and March 2007 at the Baskent University, Department of Ophthalmology were enrolled. The study protocol and informed consent were approved by the Ethics Committee at Başkent University Faculty of Medicine. Patients with major systemic or ocular surface diseases and with a history of an earlier ocular surgery or trauma, glaucoma, or known hypersensitivity to human blood products and/or fibrin glue were excluded from the study. Also, patients using artificial tears, topical or systemic steroids, or non-steroidal anti-inflammatory agents were not included. Patients were informed about the design of the study and procedure, and written informed consent was obtained from all patients.

The pterygia were graded by an independent observer (MB) during the first examination, according to the grading system used by Tan et $a l^{17}$ as atrophic (type 1), minimal inflammation (type 2), and moderate/severe inflammation or showing active growth (type 3 ). Randomisation was accomplished by using a list created by a random number generator into either of the two treatment groups in a masked manner, with patients not being informed of the surgical procedure they received, nor of their pterygium grade status. The same surgeon (CK) performed all surgeries under the operating microscope and he was instructed which method to use only after he had completed the excision of pterygium. If the patient had bilateral pterygium, one eye was selected randomly and included in the study.

\section{Amniotic membrane preparation}

The preparation and preservation of human amniotic membrane was carried out as previously described by Tseng et al. ${ }^{18}$ The membrane was taken from the preservation medium before transplantation and transferred to the surgical site after reaching room temperature.

\section{Fibrin glue preparation}

Tisseel VH (Baxter AG, Vienna, Austria), a commercially available 2-component fibrin glue was prepared according to the manufacturers' directions. The dual injection system (Duploject, Baxter AG, Vienna, Austria) was used to apply the glue, in which the fibrinogen and thrombin solution were attached separately by different syringes and were mixed only during the application onto the ocular surface.

\section{Surgical technique}

Topical $0.5 \%$ proparacaine $\mathrm{HCl}$ (Alcaine, Alcon, Hünenberg, Switzerland) was applied and subconjunctival lidocaine $\mathrm{HCl} 40 \mathrm{mg} / 2 \mathrm{ml}$ + epinephrine $0.025 \mathrm{mg} / \mathrm{ml}$ (Jetokain, Adeka, Samsun, Turkey) was injected into the body of the pterygium for anaesthesia. 
The pterygium and underlying fibrous tissue were excised thoroughly, and abnormal scar tissue on the corneal surface was polished. Minimal cauterisation was used to control the bleeding. The size of the bare scleral bed (in $\mathrm{mm}^{2}$ ) was measured in the position that the eye deviated away from the side of the lesion in order to have a maximum area of defect. Amniotic membrane was taken out of the preservation medium, marked with gentian violet, and cut to the proper size to cover the defect area. In 38 eyes, the membrane was attached to the conjunctival edges and episclera with interrupted 8-0 vicryl sutures (8-10 sutures). Fibrin glue was used in 32 eyes, for that, the membrane was placed over the cornea with the epithelial/basement membrane surface on top. After the bare scleral area was dried with a cellulose sponge, fibrin glue was applied onto scleral surface and spread with the cannula of the dual injection system. The membrane was transferred immediately over the scleral bed and fixated by pinching the edges of the membrane together with the surrounding conjunctiva. Also, the fibrin glue underneath the graft was spread with a muscle hook and excess glue was trimmed using Westcott scissors. The stability of the membrane was checked with a cellulose sponge, and additional glue was applied if necessary (Figure 1). Subconjunctival triamcinolone $(0.2 \mathrm{ml}, 40 \mathrm{mg} / \mathrm{ml})$ was injected at the end of the procedure at the inferior fornix. The eyes were patched with topical antibiotic (Tobrex, Alcon,

Hünenberg, Switzerland) ointment. Operating time was measured starting from the placement of the lid retractor to its removal at the end of the surgery.

\section{Post-operative follow-up}

After surgery, biomicroscopic examination was performed on the first day, and topical antibiotic (ofloxacin 0.3\%; Allergan Pharmaceuticals, Dublin, Ireland) and steroid (dexamethasone $0.1 \%$; Alcon, Fort Worth, TX, USA) drops were given four times daily. Patients were examined weekly and the medications were tapered and discontinued until the end of the first month. All patients were required to wear a protective eye shield for 14 days after surgery. The patients were followed up monthly for the first 6 months and at 3month intervals thereafter by the same investigator (AK). The sutures were removed at the second post-operative
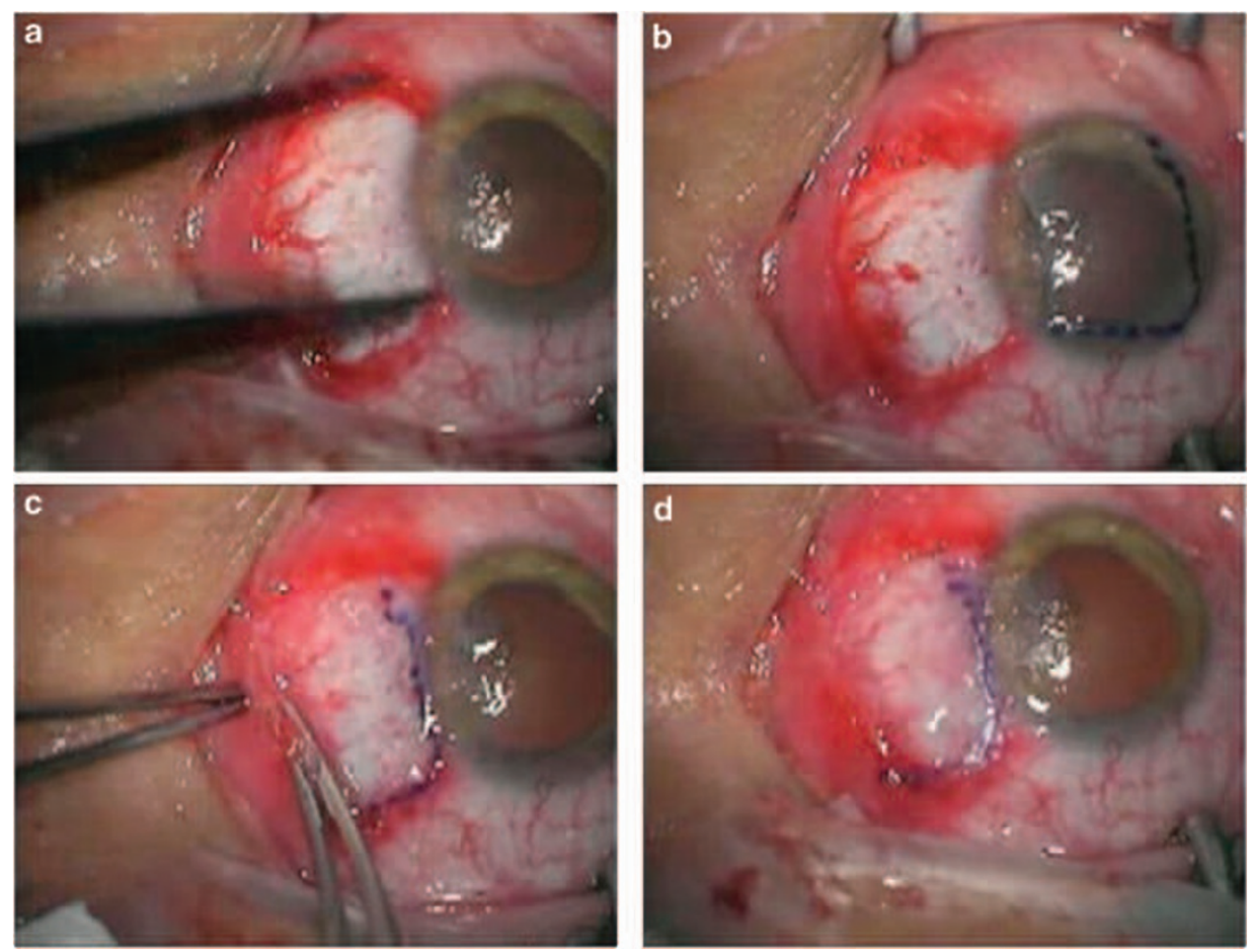

Figure 1 Surgical steps of amniotic membrane transplantation using fibrin glue (Tisseel VH) in pterygium surgery. (a) The bare scleral defect was measured with caliper after the excision of the pterygium. (b) Amniotic membrane was marked with gentian violet to ensure that a proper-sized graft, which would cover the defect area, was obtained. The membrane was placed over the cornea with the epithelial/basement membrane side on top. (c) Immediately after the application of fibrinogen and thrombin solutions onto the scleral surface, the membrane was slid over the scleral bed and the edges were 'pinched' together with the recipient conjunctiva using a smooth forceps. (d) The stability of the membrane was checked with a cellulose sponge, and additional glue was applied if necessary. 
Table 1 Demographic data of the patients in the fibrin glue and suture groups

\begin{tabular}{lccc}
\hline & Fibrin glue group $(\mathrm{n}=32)$ & Suture group $(\mathrm{n}=38)$ & \\
\hline Gender & & & P-value \\
Men & $17(53 \%)$ & $20(53 \%)$ & 0.74 \\
Women & $15(47 \%)$ & $18(47 \%)$ & 0.69 \\
& & & \\
Age (years) & $52.7 \pm 9.8^{\mathrm{a}}(35-72)$ & $54.2 \pm 11.3(37-73)$ & \\
& & & \\
Pterygium type & $7 / 32(21.9 \%)$ & $9 / 38(23.7 \%)$ & 0.31 \\
Type 1 (atrophic) & $16 / 32(50.0 \%)$ & $20 / 38(52.6 \%)$ & 0.44 \\
Type 2 & $9 / 32(28.1 \%)$ & $9 / 38(23.7 \%)$ & 0.58 \\
Type 3 (inflamed) & $14.3 \pm 7.6$ & $13.7 \pm 8.3$ & 0.73 \\
Size of bare scleral defect $\left(\mathrm{mm}^{2}\right)$ & & & \\
\hline
\end{tabular}

${ }^{\mathrm{a}}$ Mean \pm SD.

week, after the epithelialisation of amniotic membrane was completed. Snellen visual acuity, intraocular pressure measurements, slit lamp, and fundus examinations were performed at each examination.

Patients were asked to fill out a questionnaire at each visit during the first month, which includes a grading of their symptoms (pain, foreign body sensation, irritation, and epiphora) using a five-point scale, such as ${ }^{19} 0$ : none, no symptom; 1: very mild, presence of the symptom but easily tolerated; 2 : mild, symptom causing some discomfort; 3: moderate, symptom that partially interferes with usual activity or sleep; 4 : severe, symptom that completely interferes with usual activity or sleep.

Photographs of the anterior segment were taken at each control examination. Images at the final examination were graded according to the grading system based on recurrence and cosmetic appearance. ${ }^{20}$ According to this, grade 1 indicated no difference from normal appearance, whereas grade 2 indicated the presence of thin episcleral vessels in the excised area extending to but not passing the limbus, with an absence of fibrous tissue. A grade 3 classification was made if fibrous tissue did not invade the cornea. A classification of grade 4, however, indicated frank recurrence in which the fibrovascular tissue invaded the cornea.

\section{Statistical analysis}

The sample size in this study was calculated based on the recurrence rates in the study of Koranyi et al., ${ }^{5}$ which used the same type of fibrin glue (Tisseel) and sutures (Vicryl, Johnson\&Johnson, Somerville, NJ, USA).

$$
\text { Sample size }=\left[(\mathrm{Z} \alpha+\mathrm{Z} \beta)^{2} 2 P(1-P)\right] / D^{2}
$$

where $P=\left(P_{1}+P_{2}\right) / 2 ; D=P_{1}-P_{2} ; Z \alpha=$ type 1 error $(5 \%)$; $\mathrm{Z} \beta=$ type 2 error $(20 \%) ; P_{1}=$ recurrence rate in the fibrin glue group $=0.053(5.3 \%) ; P_{2}=$ recurrence rate in the suture group $=0.135(13.5 \%)$.

Statistical analyses were carried out with SPSS software (Statistical Package for the Social Sciences, version 9.0, SPSS Inc., Chicago, IL, USA). Data are reported as mean \pm SD or frequency (\%). The MannWhitney $U$ and $\chi^{2}$-tests were applied, as appropriate, to compare variables. A $P$-value $<0.05$ was considered statistically significant.

\section{Results}

All patients completed the 12-month follow-up and none of them was excluded from the study. Demographic data of patients in both groups are displayed in Table 1. In the fibrin glue group (group 1), there were 17 males and 15 females with a mean age of $52.7 \pm 9.8$ years (range, 35-72 years). The suture group (group 2) included 20 males and 18 females with a mean age of $54.2 \pm 11.3$ years (range, 37-73 years). There were no statistically significant differences regarding age or gender between groups $(P>0.05)$. Also, the difference between groups with respect to pterygium types and mean scleral defect size were not significant $(P>0.05)$.

Table 2 shows the mean follow-up periods, surgery times and clinical outcomes among groups. No statistically significant difference between groups was found regarding the follow-up period ( $P=0.38$ ). The mean operative time was significantly shorter in the fibrin glue group than in the suture group $(P=0.018)$. During the follow-up period, corneal recurrence (grade 4) was developed in three eyes $(9.4 \%)$ in the fibrin glue group, whereas in four eyes (10.5\%) in the suture group. At the end of the follow-up, final appearance as grade 3 (conjunctival recurrence) was observed in seven eyes (21.9\%) in the fibrin glue group, and in nine eyes $(23.7 \%)$ in the suture group. No statistically significant differences between groups were found for corneal and conjunctival recurrence rates, and time to 
Table 2 Patients' follow-up periods, clinical and cosmetic outcome measures in both groups

\begin{tabular}{lccc}
\hline & Fibrin glue group $(\mathrm{n}=32)$ & Suture group $(\mathrm{n}=38)$ & P-value \\
\hline Follow-up period (months) & $18.4 \pm 2.5^{\mathrm{a}}(14-22)$ & $19.6 \pm 3.8(15-25)$ & 0.38 \\
Operative time (minutes) & $11.2 \pm 2.4(8-15)$ & $18.7 \pm 2.2(14-24)$ & $4 / 38(10.5 \%)$ \\
Recurrence rate (Grade 4) & $3 / 32(9.4 \%)$ & $7.6 \pm 1.3(6-9)$ & 0.018 \\
Time to recurrence (months) & $6.3 \pm 1.5(5-8)$ & & 0.33 \\
Grade & & $15 / 38(39.5 \%)$ & 0.11 \\
1 & $12 / 32(37.5 \%)$ & $10 / 38(26.3 \%)$ & 0.27 \\
2 & $10 / 32(31.2 \%)$ & $9 / 38(23.7 \%)$ & 0.73 \\
3 & $7 / 32(21.9 \%)$ & & 0.38 \\
\hline
\end{tabular}

${ }^{\mathrm{a}}$ Mean $\pm \mathrm{SD}$.
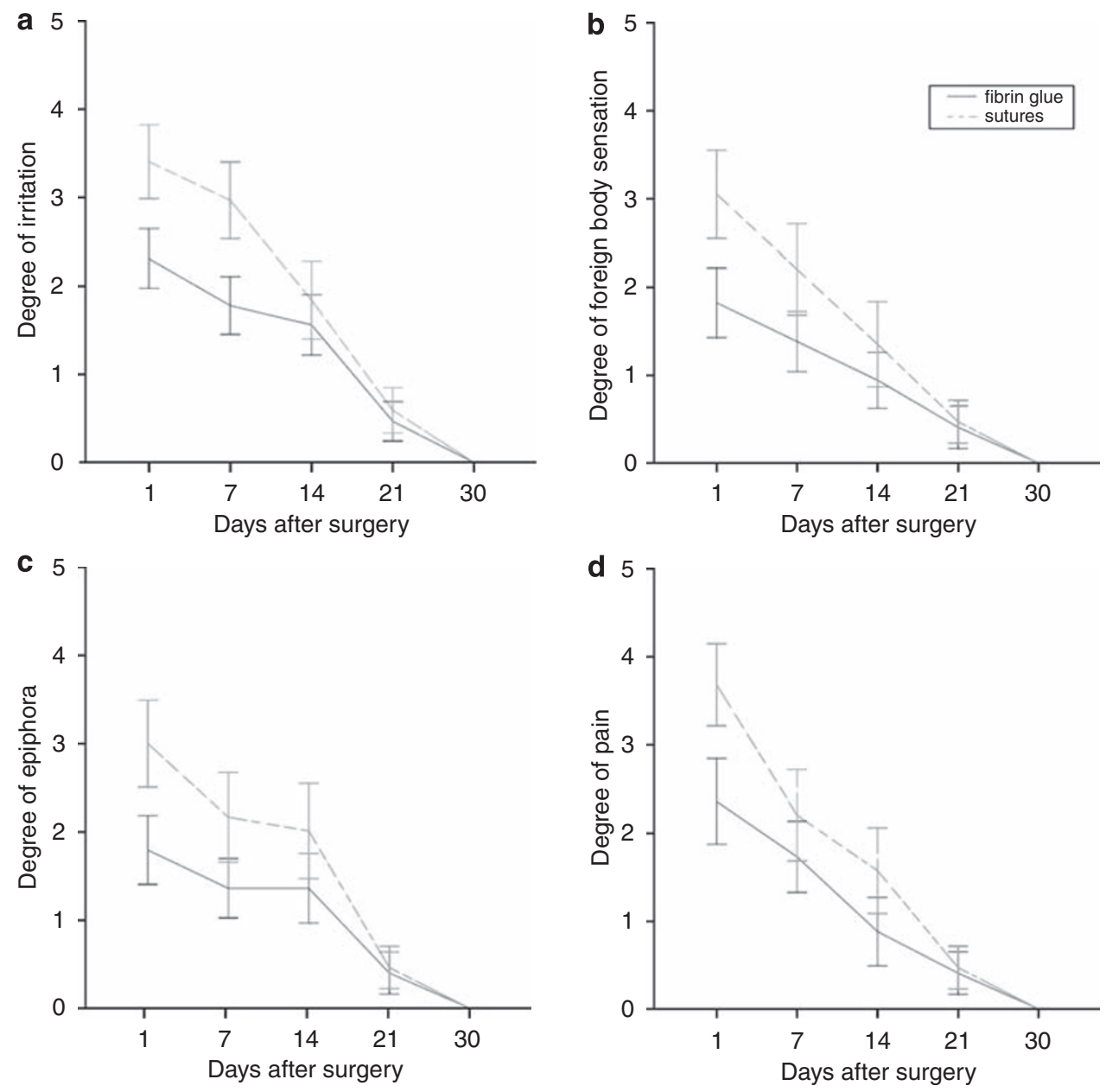

Figure 2 Five-point scale assessment of post-operative irritation (a), foreign body sensation (b), epiphora (c), and pain (d) after pterygium surgery at days $1,7,14,21$, and 30 .

recurrence ( $P=0.33, P=0.38, P=0.11$, respectively). No re-operation was necessary during the follow-up period in both groups.

The results of the self-report questionnaires are shown in Figure 2. Significantly lower post-operative scores for all symptoms (pain, epiphora, foreign body sensation, and irritation) were found in the fibrin glue group compared with the suture group at days 1, 7, and 14 after surgery $(P<0.05)$. After the suture removal at the second week, all post-operative complaints decreased in the 

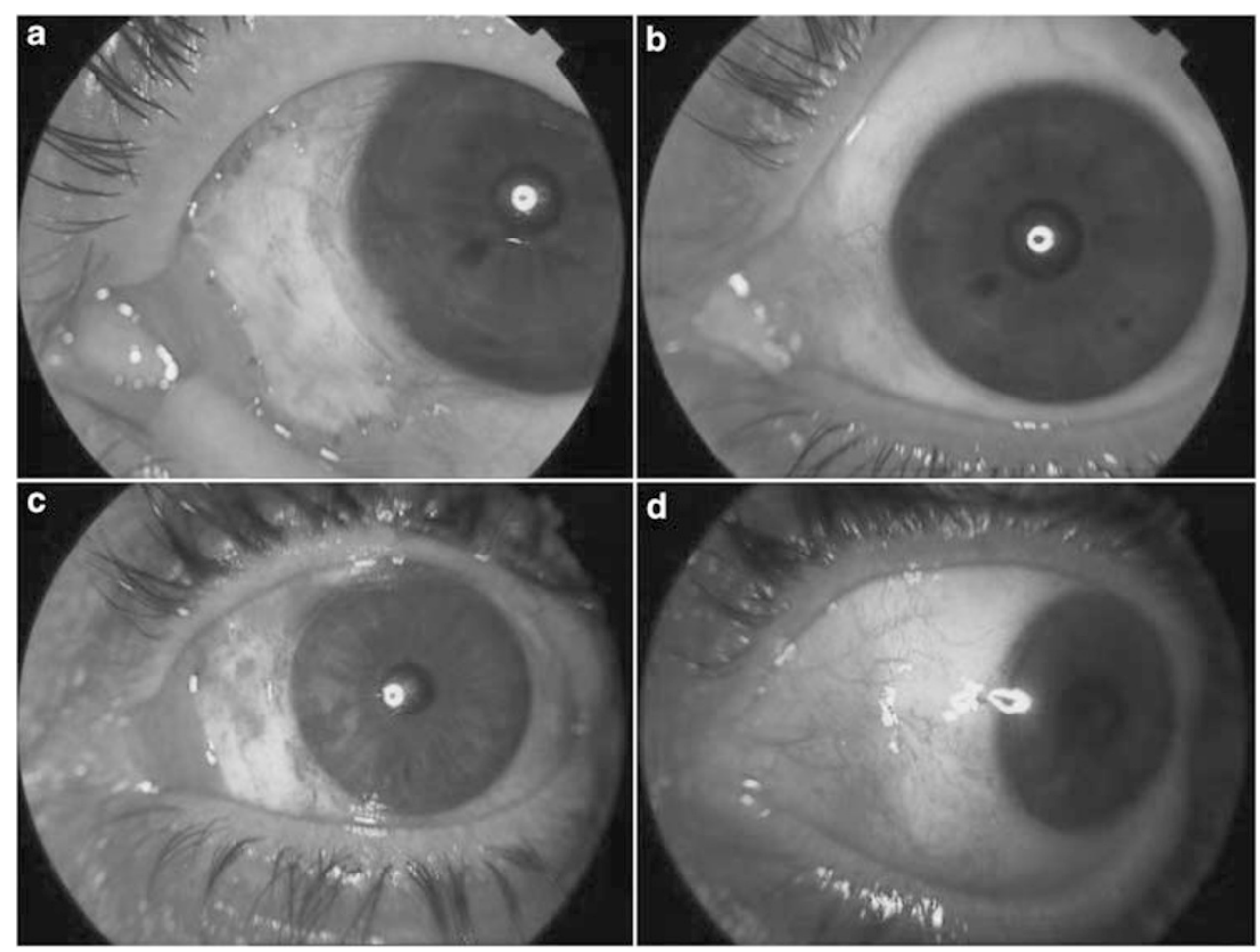

Figure 3 The anterior segment photograph of a patient in the suture group in the first post-operative week (a). At the end of the third month, a grade 2 appearance with fine episcleral vessels, which did not pass the limbus, was observed (b). Post-operative first week photograph of a well-positioned amniotic membrane graft fixated with fibrin glue (c); and a grade 1 (normal appearance) outcome at the third month $(\mathrm{d})$.

suture group and disappeared at the end of the first month in both groups.

Post-operative appearances at the first week and third month in both groups are shown in Figure 3. Fluorescein staining revealed complete epithelialisation of the amniotic membrane graft within 7 days postoperatively in all patients. In the fibrin glue group, no graft dehiscence or detachment of the membrane was observed during the follow-up period. Also, the patients in the suture group had no suture exposure or related complication, which could lead to early suture removal and re-operation in any patient.

\section{Discussion}

The primary objectives in pterygium surgery are to remove the fibrovascular growth that will eventually produce permanent scarring in the pupillary axis and to reduce recurrence. In addition, the surgeon should aim to minimise surgery-related complications, increase patient comfort in the post-operative period, and achieve an acceptable cosmetic outcome. However, the various modalities used in the treatment of pterygium have focused mainly on reducing the recurrence rate.
Among the attempts to optimise pterygium surgery, sutureless graft fixation techniques that aimed to avoid inflammatory suture-related complications, such as granuloma, abscesses, and giant papillary conjunctivitis, have been recently popularised.

Currently, human fibrin glues have additional useful applications in ophthalmic surgery to minimise the use of sutures and prevent suture-related complications. They have been used in a wide array of ophthalmic procedures, such as conjunctival closure in strabismus, vitreoretinal, and glaucoma surgery. ${ }^{21-23}$ Unfortunately, transmission of viruses (parvovirus B19, hepatitis, and human immunodeficiency virus) or Creutzfeld-Jacob agent during surgery continues to be a theoretic risk despite viral inactivation techniques.. ${ }^{24}$ Although we found no documented cases of viral transmission with Tisseel use in the literature, the possibility cannot be totally excluded. In this study, we informed all patients about these risks and observed no symptomatic clinical infection during the follow-up.

The earlier report of Jain $e t a l^{15}$ has shown the average surgical time with the use of fibrin glue as $15.5 \mathrm{~min}$, which was comparable with the current study $(11.2 \mathrm{~min}$ for the fibrin glue group). Although the authors did not 
perform a statistical evaluation of the symptom scores, they stated that the post-operative period was generally comfortable in all patients. In our study, we used the same five-point scale and observed significantly fewer symptoms with the use of fibrin glue compared with suturing. These findings were also consistent with the studies of CA using fibrin glue, in which a number of different symptom scales have been used. ${ }^{4-8}$ Shortening the surgery time and improving post-operative comfort may have several advantages. First, the use of fibrin glue removes the need for the tedious suturing process, the learning curve can be shortened, and better results may be more consistently achieved despite differences in surgical expertise. Second, more rapid and efficient surgery may reduce the risk of infection and save the surgeon and the facility valuable operating room time. And third, from the patient's standpoint, greater comfort allows a more rapid return to their normal lifestyle and productivity.

In this study, we aimed to conduct a double-blinded study to lower the bias, however, it was obviously not possible to achieve this completely because one may see the sutures in the early post-operative period looking at the mirror. Nevertheless, all patients were informed by the same investigator with the same pre-operative explanation about the side effects of surgical procedure, but they were unaware of the possible differences in post-operative symptoms with the use of fibrin glue or sutures. This effort to mask the patients was also performed in earlier studies. ${ }^{5-8}$

When fibrin glue is used, the retraction of the host conjunctiva or graft may result in gap formation between the graft in the early post-operative period. It is suggested that rapid epithelisation of the amniotic membrane prevents post-operative inflammation and thereby reduces the recurrence rate. ${ }^{18}$ Therefore, attempts such as 'tucking-in' the amniotic membrane under the surrounding conjunctiva or pinching it together with the recipient conjunctiva were tried to achieve good apposition. ${ }^{15-16}$ We have also pinched the amniotic membrane at the margins with host conjunctiva and did not observe any gap formation in the post-operative period, which would result in delayed epithelisation. Hence, epithelisation was complete within the first week in all eyes.

Prospective series in the literature report recurrence rates of 3-40.9\% after primary pterygium surgery using sutured AMT. ${ }^{2}$ Ma et $a l^{25}$ have found that single-layered amniotic membrane was able to reduce the recurrence to $12.5 \%$, which was comparable with our study. They stated that the addition of mitomycin $\mathrm{C}$ did not further reduce the recurrence rate. Moreover, the use of mitomycin $\mathrm{C}$ may result in serious complications and is commonly reserved for the recurrent cases. Solomon et al. ${ }^{26}$ reported a lower recurrence rate $(3 \%)$ when AMT was combined with intraoperative triamcinolone. Depot steroids have been reported to be effective in decreasing post-operative inflammation and preventing pterygium recurrence. ${ }^{16,27}$ In this study, we used intraoperative triamcinolone and found the recurrence rates as $9.4 \%$ in the fibrin glue group and $10.5 \%$ in the suture group. Jain et al. ${ }^{15}$ have used the same type of fibrin glue with the current study and did not observe any corneal recurrence at 1-year follow-up. Their findings were confirmed by Kheirkhah et $a l^{16}$ who also used the same fibrin adhesive in 14 cases with pterygium and reported no recurrence. The latter study was retrospective, however, the authors have compared the results with suture fixation as in our study. They have reported two recurrences in the suture group (13 patients), and emphasised the role of suture-induced conjunctival inflammation on pterygium recurrence. Similar to our study, they have used intraoperative triamcinolone, however, have also applied mitomycin C during surgery.

It is well-known that multiple factors such as preoperative inflammatory status of pterygium tissue and age might contribute to recurrence. However, the lack of any significant difference between the patients' age, gender, and pre-operative pterygium type distribution, follow-up periods, and defect sizes that the amniotic membrane was required to cover in both the groups enabled us to make a comparison between the two graft fixation techniques regarding recurrence. Moreover, it has been shown by Hirst et $a l^{28}$ that $97 \%$ of recurrences after primary pterygium surgery develop in 1 year. In our study, all patients in both groups have completed the 12-month follow-up, and all of the recurrences occured within 1 year after surgery. The mean time to recurrence in the fibrin glue group was not significantly different from the suture group (6.3 vs 7.6 months). According to our results, the use of fibrin glue seems to have no additional lowering effect on pterygium recurrence, however, the lack of recurrent cases does not allow us to make any conclusive comment regarding this issue.

In this study, we achieved similar cosmetic success with either fixation technique as shown by the percentage of eyes reaching grade 3 at the end of the follow-up (21.9 vs $23.7 \%$ ). These findings were consistent with earlier studies that concluded that final cosmetic outcomes after CA were better than AMT. ${ }^{18,20}$ This difference was explained by replacing the abnormal conjunctival epithelium of the pterygium tissue with the normal healthy conjunctiva in CA. Although the rates of grade 3 recurrence reported by Jain et al. ${ }^{15}$ and Kheirkhah et al. ${ }^{16}$ were lower than our study, the variation in study settings, together with the modification of the surgery and additional mitomycin $\mathrm{C}$ use may be responsible for this difference. In our study, we did not observe any graft 
dislocation which could lead to graft failure. Also, any progression in eyes with grade 3 appearance to corneal recurrence was not observed during the follow-up. In studies by Ma et al..$^{25}$ and Solomon et al. ${ }^{26}$ the overall (conjunctival and corneal) recurrence rates after AMT were reported as $25 \%$ (12 of 48 eyes) and $28.6 \%$ ( 6 of 21 eyes), respectively. The findings of our study regarding overall recurrence were higher (10/32, 31.2\% in fibrin glue group and $13 / 38,34.2 \%$ in suture group), but comparable to these studies. Similarly, another study by Prabhasawat et al ${ }^{18}$ showed $32.6 \%$ (15 of 46 eyes) grade 3 and 4 recurrence after primary pterygium removal with AMT. However, it should be kept in mind that a direct comparison of the recurrence rates with earlier studies could be misleading because of the influencing factors, such as unreported variation in surgical technique, demographic differences, and sample sizes. Moreover, even if our results were consistent with other study results regarding recurrence, one must not confuse the statistical significance with the clinical significance, since approximately one-third of the patients had cosmetically unacceptable appearance (grade 3 and 4) at the end of the follow-up period. As we have reported earlier, CA yields better final cosmetic results than AMT. ${ }^{20}$ Therefore, even if the recurrence rates and cosmetic results were similar in both groups of the current study, one must remind that neither represents best results when compared with CA technique. However, we also believe that AMT is a useful alternative to $\mathrm{CA}$ with advantages of restoring large excised areas and reserving conjunctiva for future surgeries.

In summary, we compared the surgical results of sutureless AMT using a fibrin adhesive with the conventional suture fixation of the membrane and shown that the use of fibrin glue was safe and effective with no major complications. The shorter operating time and increased patient comfort were the main advantages of the fibrin glue. However, using fibrin glue did not further reduce the recurrence rate or improve the final cosmetic outcome of AMT with suture fixation. A further randomised trial including recurrent pterygia is underway to confirm these findings.

\section{References}

1 Ang LP, Chua JL, Tan DT. Current concepts and techniques in pterygium treatment. Curr Opin Ophthalmol 2007; 18: 308-313.

2 Gomes JA, Romano A, Santos MS, Dua HS. Amniotic membrane use in ophthalmology. Curr Opin Ophthalmol 2005; 16: 233-240.

3 Wong VW, Rao SK, Lam DS. Polyglactin sutures versus nylon sutures for suturing of conjunctival autograft in pterygium surgery: a randomized, controlled trial. Acta Ophthalmol Scand 2007; 85: 658-661.

4 Marticorena J, Rodriguez-Ares MT, Tourino R, Mera P, Valladares MJ, Martinez-de-la-Casa JM et al. Pterygium surgery; conjunctival autograft using fibrin adhesive. Cornea 2006; 25: 34-36.

5 Koranyi G, Seregard S, Kopp ED. The cut and paste method for primary pterygium surgery: long-term follow-up. Acta Ophthalmol Scand 2005; 83: 298-301.

6 Uy HS, Reyes JMG, Flores JDG, Lim-Bon-Siong R. Comparison of fibrin glue and sutures for attaching conjunctival autografts after pterygium excision. Ophthalmology 2005; 112: 667-671.

7 Bahar I, Weinberger D, Gaton DD, Avisar R. Fibrin glue versus vicryl sutures for primary conjunctival closure in pterygium surgery: long-term results. Curr Eye Res 2007; 32: 399-405.

8 Karalezli A, Kucukerdonmez C, Akova YA, Altan-Yaycioglu $\mathrm{R}$, Borazan M. Fibrin glue versus sutures for conjunctival autografting in pterygium surgery: a prospective comparative study. Br J Ophthalmol 2008; 92: 1206-1210.

9 Hick S, Demers PE, Brunette I, La C, Mabon M, Duchesne B. Amniotic membrane transplantation and fibrin glue in the management of corneal ulcers and perforations: a review of 33 cases. Cornea 2005; 24: 369-377.

10 Szurman P, Warga M, Grisanti S, Roters S, Rohrbach JM, Aisenbrey $\mathrm{S}$ et al. Sutureless amniotic membrane fixation using fibrin glue for ocular surface reconstruction in a rabbit model. Cornea 2006; 25: 460-466.

11 Uhlig CE, Busse H, Groppe M. Use of fibrin glue in fixation of amniotic membranes in sterile corneal ulceration. Am J Ophthalmol 2006; 142: 189-191.

12 Sekiyama E, Nakamura T, Kurihara E, Cooper LJ, Fullwood NJ, Takaoka $\mathrm{M}$ et al. Novel sutureless transplantation of bioadhesive-coated, freeze-dried amniotic membrane for ocular surface reconstruction. Invest Ophthalmol Vis Sci 2007; 48: 1528-1534.

13 Kheirkhah A, Casas V, Blanco G, Li W, Hayashida Y, Chen YT et al. Amniotic membrane transplantation with fibrin glue for conjunctivochalasis. Am J Ophthalmol 2007; 144: 311-313.

14 Pfister RR, Sommers CI. Fibrin sealant in corneal stem cell transplantation. Cornea 2005; 24: 593-598.

15 Jain AK, Bansal R, Sukhija J. Human amniotic membrane transplantation with fibrin glue in management of primary pterygia: a new tuck-in technique. Cornea 2008; 27: 94-99.

16 Kheirkhah A, Casas V, Sheha H, Raju VK, Tseng SC. Role of conjunctival inflammation in surgical outcome after amniotic membrane transplantation with or without fibrin glue for pterygium. Cornea 2008; 27: 56-63.

17 Tan DT, Chee SP, Dear KBG, Lim AS. Effect of pterygium morphology on pterygium recurrence in a controlled trial comparing conjunctival autografting with bare sclera excision. Arch Ophthalmol 1997; 115: 1235-1240.

18 Prabhasawat P, Barton K, Burkett G, Tseng SC. Comparison of conjunctival autografts, amniotic membrane grafts, and primary closure for pterygium excision. Ophthalmology 1997; 104: 974-985.

19 Lim-Bon-Siong R, Valluri S, Gordon M, Gordon ME, Pepose JS. Efficacy and safety of the ProTek (Vifilcon A) therapeutic soft contact lens after photorefractive keratectomy. Am J Ophthalmol 1998; 125: 169-176. 
20 Kucukerdonmez C, Akova YA, Altinors DD. Comparison of conjunctival autograft with amniotic membrane transplantation for pterygium surgery. Cornea 2007; 26: 407-413.

21 Biedner B, Rosenthal G. Conjunctival closure in strabismus surgery: vicryl versus fibrin glue. Ophthalmic Surg Lasers 1996; 27: 967.

22 Kajirawa K. Repair of a leaking bleb with fibrin glue. Am J Ophthalmol 1990; 109: 599-601.

23 Mentens R, Stalmans P. Comparison of fibrin glue and sutures for conjunctival closure in pars plana vitrectomy. Am I Ophthalmol 2007; 144: 128-131.

24 Chan SM, Boisjoly H. Advances in the use of adhesives in ophthalmology. Curr Opin Ophthalmol 2004; 15: 305-310.
25 Ma DH, See LC, Liau SB, Tsai RJ. Amniotic membrane graft for primary pterygium: comparison with conjunctival autograft and topical mitomycin $\mathrm{C}$ treatment. $\mathrm{Br} \mathrm{J}$ Ophthalmol 2000; 84: 973-978.

26 Solomon A, Pires RTF, Tseng SCG. Amniotic membrane transplantation after extensive removal of primary and recurrent pterygia. Ophthalmology 2001; 108: 449-460.

27 Paris Fdos S, de Farias CC, Melo GB, Dos Santos MS, Batista JL, Gomes. Postoperative subconjunctival corticosteroid injection to prevent pterygium recurrence. Cornea 2008; 27: 406-410.

28 Hirst LW, Sebban A, Chant D. Pterygium recurrence time. Ophthalmology 1994; 101: 755-758. 